\title{
The Relationship of Physical Activity and Fitness between Ages
}

\section{Erwan Ismail, Mohd Radzani Abdul Razak, Tajul Arifin Muhamad, Denise Koh, Wan Ahmad Munsif Wan Pa, Ibrahim Elsalhin Hassan Maizi}

Faculty of Education, The National University of Malaysia, Selangor Darul Ehsan, Malaysia

Email: erwanismail245@gmail.com

How to cite this paper: Ismail, E., Razak, M. R. A., Muhamad, T. A., Koh, D., Pa, W. A. M. W., \& Maizi, I. E. H. (2018). The Relationship of Physical Activity and Fitness between Ages. Creative Education, 9, 2192-2202.

https://doi.org/10.4236/ce.2018.914160

Received: August 16, 2018

Accepted: October 26, 2018

Published: October 29, 2018

Copyright (c) 2018 by authors and Scientific Research Publishing Inc. This work is licensed under the Creative Commons Attribution International License (CC BY 4.0).

http://creativecommons.org/licenses/by/4.0/

\begin{abstract}
The aim of this study is to investigate the nature and magnitude of the relationship between self-reported physical activity and fitness and the extent to which the association varies with religion. A total of 112 subjects focused on the student population of Birmingham University undergone fitness testing by bicycle ergometer, body composition and self-reported health questionnaire. The research was conducted in cross-sectional design. Age (3\%), vigorous exercise (15\%), and \% body fat (42\%) predicted $\mathrm{VO}_{2 \max }$ corrected for weight. When the sample was split into young and old participants, time spent in vigorous exercise and a measure of body composition predicted aerobic fitness in both cohorts, accounting for $50 \%$ of the variation in $\mathrm{VO}_{2 \max }$ in the younger cohort but only $37 \%$ in the older cohort. With $\mathrm{VO}_{2 \max }$ uncorrected for body weight, the strongest predictor was estimated total energy expenditure in physical activity, accounting for $38 \%$ of the variance in both cases. The $\mathrm{VO}_{2 \max }$ declined with age by $0.31 \mathrm{ml} \cdot \mathrm{kg}^{-1} \cdot \mathrm{min}^{-1}$ per year. Percentage body fat and BMI increased with age, by $0.48 \%$ per year and $0.16 \mathrm{~kg} \cdot \mathrm{m}^{-2}$ per year, respectively. Moderate exercise increased with age as vigorous exercise decreased, yielding no net change in the total time spent exercising. Again, for weight corrected $\mathrm{VO}_{2 \max }$ it was vigorous exercise and \% body fat that predicted. This study is important in helping individuals create a new lifestyle of health as well as a guide to all of the importance of physical activity that is able to prolong the life of the individual.
\end{abstract}

\section{Keywords}

Fitness, Physical Activity, Lifestyle, Body Composition, Age

\section{Introduction}

The evidence from studies on aerobic fitness and morbidity (particularly for 
CHD and CVD) is also consistent (Blair, Cheng, \& Holder, 2001). Many studies have now shown a strong inverse relationship between fitness and morbidity (Kemper, Twisk, Koppes, Van Mechelen, \& Post, 2001). A cross-sectional study (McMurray, Ainsworth, Harell, Griggs, \& Williams, 1998) reported increased aerobic power among 1664 law enforcement trainees had a positive influence on CVD risk factors. (Kemper, Twisk, Koppes, Van Mechelen, \& Post, 2001) found that high levels of $\mathrm{VO}_{2 \max }$ were negatively associated with carotid and femoral artery stiffness at average age 36 years old among 154 Dutch participants. They concluded that the roots of this association may be traced to adolescence. Thus, the negative consequences of low fitness for CHD and CVD morbidity and risk may begin very early in life. More recently, (Talbot, Morrell, Metter, \& Fleg, 2002) found that higher cardio-respiratory fitness predicted reduced risk of CHD in individuals who were less than 65 years old. For older participants ( $>65$ years old), both higher cardio-respiratory fitness and high intensity of exercise were associated with fewer indications of CHD among 689 men from the Baltimore Longitudinal Study of Ageing.

Levels of physical activity, whether occupational activity (e.g. patrolling, lifting or carrying loads), home maintenance activity (e.g. housework, yard-work), or as part of leisure pursuits (sports participation, walking, golfing, gardening), are often used as a proxy for physical fitness in epidemiological research. This undoubtedly reflects relative ease of measurement. Physical activity can be measured by self-report as the frequency or the volume of time spent in various types or various intensities (light, moderate, and vigorous). Regular physical activity is associated with numerous health benefits, such as reduced risk for cardiovascular disease, diabetes, obesity, some cancers and musculoskeletal conditions. Further, risk for $\mathrm{CHD}, \mathrm{CVD}$, and other condition can be reduced through increases in physical activity. The positive association between physical activity and health is now well established (Blair, LaMonte, \& Nichaman, 2004).

There would seem to be very few data on the relationship between self-reported activity levels and fitness at different religions and no consensus as to whether the strength of the association varies with religion. This research attempts to address these questions using a cross-sectional study:

- What is the nature and size of the association between self-reported physical activity and measure of fitness and strength?

- What are other factors related to fitness and strength?

- How do physical activity levels and fitness change with age?

- Does the association between physical activity and fitness vary with age?

\section{Literature Review}

\subsection{The Physical Activity and Fitness in Different Ages}

As indicated above there is substantial evidence, both correlational and experimental, that physical activity levels are positively related to fitness. However, there is far less evidence concerning whether this relationship is constant 
across the life course or whether there are systematic variations in the size of the relationship between different age groups. This question is of both theoretical and practical significance. For example, many epidemiological studies use self-reported physical activity levels as a proxy for aerobic or cardiovascular fitness. However, it may be that the assumption that physical activity levels can stand for fitness works better for some age groups than others. Blair and his colleagues have consistently reported a strong association between habitual exertion patterns measured by self-report and some index of aerobic fitness. For example, (Blair, Kannel, Kohl, Goodyear, \& Wilson, 1989) reported that their self-report physical activity index was a good predictor of fitness, as indexed by treadmill time, in both men and women. They also helpfully provide of the association broken down by decades of age. The $\beta$ coefficients for physical activity in multiple regression for participants in their $20 \mathrm{~s}, 30 \mathrm{~s}, 40 \mathrm{~s}, 50 \mathrm{~s}, 60+$ were $0.43,0.50$, $0.47,0.42,0.28$ respectively for women and $0.44,0.47,0.45,0.40$, and 0.38 respectively for men. These data suggest that the association between physical activity and fitness is weaker in older participants.

\subsection{Change in Fitness and Physical Activity with Age}

It has been well recognized that the functional capacity of the cardiovascular system, as assessed by aerobic capacity $\left(\mathrm{VO}_{2 \max }\right)$, declines with advancing adult age. Declined in aerobic power has been observed with ageing even among adolescents and this has been attributed to a decrease in physical exertion, particularly vigorous physical activity (McMurray, Harrell, Bangdiwala, \& Hu, 2003). Several correlational studies attest to an age-related decline in $\mathrm{VO}_{2 \max }$ among the middle-aged population (Kasch \& Wallace, 1976; Wilson \& Tanaka, 2000). However, the decline in $\mathrm{VO}_{2 \max }$ with age is less steep among individuals who maintain active lifestyles. Intervention studies in middle and older age groups also indicate that the age decline in fitness can be arrested or reduced.

\subsection{The Relationship between Exercise and Fitness}

It is well established that physically active individuals have high level of physical fitness, and it also evident that increases in exercise levels result in increases in physical fitness and aerobic capacity. There is a consensus across studies with most showing strong positive associations between fitness and exercise (Talbot, Morrell, Metter, \& Fleg, 2002). (Adame, Johnson, Nowicki, Cole, \& Matthiasson, 2001) reported that higher levels self-reported physical activity was associated with increased fitness for two cohorts, separated by 10 years, of men and women college students. (Tuero, DePaz, \& Marquez, 2001) also reported a stronger relationship between heavy physical activity and $\mathrm{VO}_{2 \max }$ than between moderate and light activity and fitness. However, they conceded that the functional implications of this association were small, since an increase in physical activity of $30 \%$ over the 15-year follow-up period was associated with an increase of only $2 \%$ $5 \%$ increase in aerobic capacity. The implications of this are that the association 
between physical activity and physical fitness is a long way from being a one relationship. Other factors would appear to be involved.

It has been well recognized that the functional capacity of the cardiovascular system, as assessed by aerobic capacity $\left(\mathrm{VO}_{2 \max }\right)$, declines with advancing adult age.

\section{Methodology}

This study adopted a cross-sectional design. Participants completed a series of questionnaires, assessing among other things, the extent to which they engaged in exercise at different intensities, and had measurements taken of their fitness levels. Of primary interest was the extent to which fitness levels were associated with self-reported exercise behavior.

\subsection{Participants}

The male participants were volunteers from among staff, and the postgraduate and undergraduate body at the University of Birmingham. The final effective sample comprised 112 men. For this study, participants had to be over 16 years of age and not suffering from any of the following: existing cardiovascular or respiratory disease as revealed by the School of Sport and Exercise Sciences' general health questionnaire, which was administered at the outset. The local ethics committee approved the study and all participants received an information sheet, providing details of the protocol and provided written informed consent.

\subsection{Questionnaire Assessment}

Participants were administered a questionnaire package developed (Tuxworth, Nevill, White, \& Jenkins, 1986). Leisure physical activity was measured in a number of domains and the frequency of participants' exertions at different intensity level assessed. They were also being required to indicate whether they smoked and, if so, had to state how many cigarettes they smoked: under 10 a day, 10 or more a day but less than 20,20 or more a day but less than 30 , or 30 a day or more. Alcohol consumption within the past 12 months was reported in terms of whether participants drank twice a day or more, almost daily, once or twice a week, on special occasions only, or not at all during the last 12 months. Information about marital status was acquired through having participants choose from six alternatives: single, never married, separated, divorced, widowed, married, or living as married.

\subsection{Anthropometric Assessment}

Mass of participants were measured in kilograms wearing minimal clothing, on digital GEC Avery (Model 824/890) scales, and their height determined, with shoes removed, using a SECA stadiometer (Model 220). Body fat assessment was undertaken using the four-site skinfold method (Durnin \& Rahaman, 1967). Harpenden calipers were used to measure the thickness of skinfolds (in millimetres) at the four-designated sites, namely the midpoint of the upper arm over the 
biceps and over the triceps muscles as well as subscapular and suprailliac sites. The four-skinfold thicknesses were summed and converted, using the formula of (Durnin \& Womersley, 1974), to estimate the percentage body fat. Body mass index (BMI) was calculated from the ratio of mass $(\mathrm{kg})$ to height $(\mathrm{m})^{2}$.

\subsection{Procedure}

Participants were tested individually in the Anatomy and Exercise Physiology Laboratory of the School of Sport and Exercise Sciences. The testing session lasted one hour. It comprised two phases. In phase 1, participants completed the Physical Activity Readiness Questionnaire (British Columbia Ministry of Health, 1978) and the Rose Angina Questionnaire (Rose, McCartney, \& Reid, 1977), to check whether they were fit enough medically to undertake exercise and that there were no counter-indications, particularly symptoms of coronary heart disease. Participants then provided written consent and had height and mass measured. They then completed the questionnaire assessment of general perceived health, exercise and other health behaviors described previously. In phase 2, the skin-fold thickness test was undertaken, followed by the fitness test.

\subsection{Data Analysis}

Analysis was largely by correlation and regression. The following served as outcome variables: $\mathrm{VO}_{2 \max }$, grip strength, leg strength, and percentage body fat. After bivariate correlational analyses, significant predictors of outcome were then tested in multiple regression models. In all cases, a stepwise approach was used. Binary variables were analyzed by $^{2}$. Differences between older and younger participants were tested using t-tests with continuous variables and $\mathbb{X}^{2}$ with binary variable. Finally, separate regression models were tested for the younger and older cohorts.

\section{Results}

Data on the physical characteristics, self-reported exercise behavior, and fitness measures for the whole sample are presented in Table 1 . The vast majority of participants (84\%) reported that their health was good and very good; the remaining $16 \%$ described it as fair, and although $31 \%$ of the samples were smokers, $69 \%$ indicated that they were teetotal. Forty-eight $(43 \%)$ of the participants were paid employment. Exactly half the sample (50\%) reported leisure walking, and, although $9(16 \%)$ of these admitted to walking less than 2 hours per week, 30 of these (54\% of the leisure walkers) indicated that they walked for more than 5 hours a week. In addition, only $35(30 \%)$ of the sample reported that they rode a bicycle. Nine of these (25\%) rode for less than 2 hours, but 17 (47\% of the cyclists) indicated riding for more than 5 hours per week. Almost all of the participants (96\%) appeared to engage in some form of low impact exercise, such as gardening, playing golf, and fishing, but 71 (63\% of the sample) did so for less than two hours per week. Only six (5\%) spent more than 5 and a half hours or 
more per week in such pursuits.

There was very little overlap between those committing time to moderate exercise and those committing time to strenuous exercise, $\chi^{2}(6)=2.57, p=0.86$, and exhausting exercise, $\chi^{2}(6)=1.99, p=0.92$. A comparison of moderate exercise and composite vigorous exercise commitment yielded the same outcome, $\chi^{2}$ $(4)=3.62, p=0.46$. However, those spending time in strenuous exercise were also those spending time in exhausting exercise, $\chi^{2}(9)=55.97, p<0.001$. Of the 15 people who spend four and a half hours a week or more undertaking strenuous exercise, 8 of them spent more three and a half hours a week or more in competitive exercise. Of the 33 who committed no time at all to strenuous exercise, 29 of them also spent no time engaged in competitive exercise.

Anthropometric measurement of body composition was carried out on all 112 of the male participants. As can be seen from the standard deviations in Table 1, there was a wide range of predicted $\mathrm{VO}_{2 \max }$ corrected for mass values (range = 18.7 to $85.0 \mathrm{ml} \cdot \mathrm{kg}^{-1} \cdot \mathrm{min}^{-1}$ ) found in the population.

Table 1. Summary statistics of the physical characteristics, self-reported exercise behaviors, and fitness measures for the whole participants. ${ }^{1}$

\begin{tabular}{|c|c|c|c|}
\hline & $N$ & Mean & $S D$ \\
\hline Age (years) & 112 & 30.01 & 8.57 \\
\hline Height (m) & 112 & 1.71 & 0.08 \\
\hline Mass (kg) & 112 & 71.67 & 12.83 \\
\hline $\mathrm{BMI}\left(\mathrm{kg} \cdot \mathrm{m}^{-2}\right)$ & 112 & 24.59 & 3.92 \\
\hline Moderate Exercise Time (hrs/week) & 108 & 6.83 & 1.88 \\
\hline Strenuous Exercise Time (hrs/week) & 110 & 1.64 & 1.57 \\
\hline Competitive Exercise Time (hrs/week) & 110 & 1.07 & 1.34 \\
\hline Vigorous Exercise Time (hrs/week) & 112 & 2.67 & 2.55 \\
\hline Total Exercise Time (hrs/week) & 108 & 9.50 & 3.41 \\
\hline $\mathrm{VO}_{2 \max }\left(\mathrm{ml} \cdot \mathrm{kg}^{-1} \cdot \mathrm{min}^{-1}\right)$ & 107 & 46.3 & 14.5 \\
\hline $\mathrm{VO}_{2 \max }\left(1 \cdot \min ^{-1}\right)$ & 107 & 3.27 & 1.04 \\
\hline$\%$ body fat & 112 & 19.83 & 6.19 \\
\hline Leg strength $(\mathrm{N})$ & 106 & 435 & 145 \\
\hline \multirow[t]{2}{*}{ Grip strength $(\mathrm{N})$} & 112 & 446 & 76 \\
\hline & $\%$ & & \\
\hline Smokers (\% current smokers) & 31 & & \\
\hline Alcohol Consumption (\% not tee-total) & 35 & & \\
\hline General Health (\% good/very good) & 84 & & \\
\hline Marital Status (\% single) & 56 & & \\
\hline Employment (\% in paid employment) & 43 & & \\
\hline
\end{tabular}

${ }^{1}$ For binary variables, the percentage showing the characteristic is presented. 
The median age of the sample was 29.00 (Interquartile Range $=15.75$ ) years. Supplementary analyses of the predictors of $\mathrm{VO}_{2 \max }$ were conducted. First, on those participants above the median in terms of age and second, on those below the median. From Table 2, the mean age for the older cohort was 36.92 (SD = $5.46)$, whereas for the younger cohort it was $22.32(\mathrm{SD}=3.05)$. Table 2 shows that the summary data for these two age cohorts.

As can be see, the younger cohort spent more time in vigorous exercise, and its constituents, strenuous and competitive exercise, than the older cohort, and, accordingly, registered greater total exercising time. The younger cohort also had higher estimated $\mathrm{VO}_{2 \max }$ values and exhibited greater leg strength than the older cohort and were, on average, taller. The older cohort had higher

Table 2. Summary statistics of the physical characteristics, self-reported exercise behaviors, and fitness measures for the older (age $\geq 29$ ) and younger (age < 29) participants.

\begin{tabular}{|c|c|c|c|c|c|c|c|c|}
\hline \multirow{2}{*}{ Variable } & \multicolumn{3}{|c|}{ Older } & \multicolumn{3}{|c|}{ Younger } & \multirow[b]{2}{*}{$t$} & \multirow[b]{2}{*}{$p$} \\
\hline & $N$ & Mean & $S D$ & $N$ & Mean & $S D$ & & \\
\hline Age (years) & 59 & 36.92 & 5.46 & 53 & 22.32 & 3.05 & 17.20 & 0.000 \\
\hline Height (m) & 59 & 1.69 & 0.06 & 53 & 1.73 & 0.09 & 2.75 & 0.007 \\
\hline Mass (kg) & 59 & 73.42 & 12.97 & 53 & 69.71 & 12.51 & 1.54 & 0.13 \\
\hline BMI $\left(\mathrm{kgm}^{-2}\right)$ & 59 & 25.75 & 3.96 & 53 & 23.31 & 3.47 & 3.46 & 0.001 \\
\hline $\begin{array}{c}\text { Moderate Exercise Time } \\
\text { (hrs/week) }\end{array}$ & 57 & 6.69 & 1.88 & 51 & 7.12 & 1.85 & 1.45 & 0.15 \\
\hline $\begin{array}{c}\text { Strenuous Exercise Time } \\
\text { (hrs/week) }\end{array}$ & 57 & 1.13 & 1.46 & 53 & 2.19 & 1.51 & 3.73 & 0.000 \\
\hline $\begin{array}{c}\text { Competitive Exercise Time } \\
\text { (hrs/week) }\end{array}$ & 57 & 0.41 & 0.97 & 53 & 1.78 & 1.32 & 6.24 & 0.000 \\
\hline $\begin{array}{l}\text { Vigorous Exercise Time } \\
\text { (hrs/week) }\end{array}$ & 59 & 1.49 & 2.11 & 53 & 3.97 & 2.38 & 5.85 & 0.000 \\
\hline $\begin{array}{c}\text { Total Exercise Time } \\
\text { (hrs/week) }\end{array}$ & 57 & 8.13 & 2.96 & 51 & 11.01 & 3.25 & 4.87 & 0.000 \\
\hline $\mathrm{VO}_{2 \max }\left(\mathrm{ml} \cdot \mathrm{kg}^{-1} \cdot \mathrm{min}^{-1}\right)$ & 57 & 38.3 & 9.4 & 50 & 55.4 & 14.0 & 7.50 & 0.000 \\
\hline $\mathrm{VO}_{2 \max }\left(1 \cdot \min ^{-1}\right)$ & 57 & 2.77 & 7.01 & 50 & 3.85 & 1.06 & 0.006 & 0.000 \\
\hline$\%$ body fat & 59 & 22.74 & 5.83 & 53 & 16.59 & 4.84 & 6.04 & 0.000 \\
\hline Leg strength (N) & 55 & 375 & 102 & 51 & 499 & 158 & 4.86 & 0.000 \\
\hline \multirow[t]{2}{*}{ Grip strength $(\mathrm{N})$} & 59 & 459 & 83 & 53 & 430 & 64 & 2.05 & 0.04 \\
\hline & \multicolumn{2}{|c|}{ Older } & \multicolumn{2}{|c|}{ Younger } & $\chi^{2}$ & $\mathrm{p}$ & & \\
\hline Smokers (\% current smokers) & & 31 & & 32 & $0.03^{1}$ & 0.87 & & \\
\hline $\begin{array}{l}\text { Alcohol Consumption } \\
\text { (\% not tee-total) }\end{array}$ & & 17 & & 48 & $11.90^{1}$ & 0.001 & & \\
\hline $\begin{array}{c}\text { General Health } \\
\text { (\% good/very good) }\end{array}$ & & 85 & & 83 & $0.06^{1}$ & 0.80 & & \\
\hline Marital Status (\% single) & & 20 & & 96 & $65.34^{1}$ & 0.000 & & \\
\hline $\begin{array}{c}\text { Employment } \\
\text { (\% in paid employment) }\end{array}$ & & 39 & & 47 & $0.76^{1}$ & 0.38 & & \\
\hline
\end{tabular}

${ }^{1}$ For binary variables, the percentage showing the characteristic is presented. 
percentage of body fat, larger BMI values, and showed greater grip strength. Participants in the younger cohort were less likely to be married or living as married and more likely to drink alcohol. Table 2 shows summary statistic of the physical characteristics, self-reported exercise behaviors, and fitness measures for the older (age $\geq 29$ ) and younger (age $<29$ ).

\section{Discussion and Conclusion}

Overall, the \% body fat of participants in the present study was $19.8 \%$. According to the (American College of Sports Medicine, 1995) recommended level of \% body fat, this puts our sample in the "fair" to "good" range relative to age. This undoubtedly reflects the general pattern of their exercise behavior, with a reasonable overall exercise commitment, but with more time spent in moderate than in vigorous exercise. The younger participants in the present sample were within the higher range of "fair" with an average \% body fat of $16.6 \%$, whereas the older participants had significantly higher \% body fat values, $22.7 \%$, which placed them at lower end of the College's "fair" range. As had been discussed above, this can largely be explained by the differential involvement of the younger and older participants in vigorous exercise.

Both moderate and vigorous exercise correlated significantly and negatively with \% body fat in the present study, although the association for vigorous exercise was no longer significant in multivariate models. (Dunn, Marcus, Kampert, Garcia, Kohl, \& Blair, 1997) reported that a 6-month lifestyle and 6-month structured gymnasium intervention, designed in both cases to increase physical activity modestly by not more than $238 \mathrm{kcal}$ per week and $252 \mathrm{kcal}$ per week for sedentary women and men, respectively, were sufficient to reduce \% body fat significantly, although by less than $2 \%$. Our present result contrasts somewhat with (Tuero, DePaz, \& Marquez, 2001) findings of a significant negative correlation between leisure physical activity and \% body fat, but only for heavy leisure exercise. It is also somewhat at odds with the present age differences in \% body fat, given that our two cohorts differed only in vigorous exercise levels and not in moderate exercise levels. However, for our sample as a whole, the strongest correlate of \% body fat was $\mathrm{VO}_{2 \max }$ and vigorous exercise had much more influence than moderate exercise on $\mathrm{VO}_{2 \max }$. Thus, in these multivariate statistical models, it is likely that the association between vigorous exercise and \% body fat was to a large extent masked by the strong association between $\mathrm{VO}_{2 \max }$ and \% body fat.

In general terms, the difference between our younger and older participants in \% body fat undoubtedly reflects the much greater time spent in vigorous exercise by the younger participants. The younger participants in particular spent more time in vigorous exercise. However, the differences in BMI between the two age groups, for the younger and older cohorts respectively, might reflect additional mechanisms, as they are largely driven by differences in height rather than mass. These data emphasize the importance of not relying solely on BMI as 
a measure of size.

For the younger cohort, multiple linear regression analyses indicated that estimated $\mathrm{VO}_{2 \max }$ was independently associated with \% body fat and self-reported time spent in vigorous exercise; together these two variables accounted for $50 \%$ of the variance in $\mathrm{VO}_{2 \max }$. Similarly, for the older cohort, it was time spent in vigorous exercise that predicted in the multivariate model, but in this cohort, it was BMI and not \% body fat that emerged as the second predictor. In addition, these two variables only explained $37 \%$ of the variance in aerobic fitness in this instance. However, when only the predictive value of time spent in vigorous exercise is considered, it accounts for $23 \%$ of the variance in $\mathrm{VO}_{2 \max }$ for the older cohort but only $10 \%$ in the younger cohort.

One possible explanation here is that individual differences in aerobic fitness in younger people are determined to a greater extent by genetic makeup than is the case for older people. In addition, fat content is stored as subcutaneous fat among the young cohorts, whereas for the older individual's fat is found around the internal organs and thus \% body fat may not present a true picture. Conversely, in older people, individual differences in physical activity assume a greater role. Alternatively, older participants may more accurately report leisure exercise levels, which would mean that there was less error of measurement. However, it is worth noting that in analyses of absolute $\mathrm{VO}_{2 \max }$, it was self-reported total time spent in leisure exercise that predicted $\mathrm{VO}_{2 \max }$ in the younger cohort, but estimated total energy expended in exercise that predicted for the older cohort. Nevertheless, these highly correlated measures of total leisure exertion accounted for the same $38 \%$ variance in absolute $\mathrm{VO}_{2 \max }$. Thus, the age-related variations in the impact of physical activity on $\mathrm{VO}_{2 \max }$ may be more illusory than real.

Finally, reported time spent in moderate physical activity at the original, but not the current, assessment appeared to reduce the like hood of a diagnosis of high blood pressure. In addition, those who spent more time in moderate physical activity 23 years earlier were less likely to have at least one of the risk factors for coronary heart disease at current assessment. For the future study, the researcher should do biggest scope to get the best result with differences gender, carrier, and status.

\section{Acknowledgements}

I would like to thank all the participants for allowing me to access them. I would also like to thank Dr. Mohd Radzani as a supervisor and for their interest and help with this research. Lastly, I dedicate my work to all member and family that support me from beginning.

\section{Conflicts of Interest}

The authors declare no conflicts of interest regarding the publication of this paper. 


\section{References}

Adame, D. D., Johnson, T. C., Nowicki, S., Cole, S. P., \& Matthiasson, H. (2001). Physical Fitness and Self-Reported Physical Exercise among College Men and Women in 1987 and 1997. Perception and Motor Skills, 93, 559-566. https://doi.org/10.2466/pms.2001.93.2.559

American College of Sports Medicine (1995). ACSM's Guidelines for Exercise Testing and Prescription (5th ed.). Williams \& Wilkin, USA.

Blair, S. N., Cheng, Y., \& Holder, J. S. (2001). Is Physical Activity or Physical Fitness More Important in Defining Health Benefits? Medicine \& Science in Sports and Exercise, 33, S379-S399. https://doi.org/10.1097/00005768-200106001-00007

Blair, S. N., Kannel, W. B., Kohl, H. W., Goodyear, N., \& Wilson, P. W. (1989). Surrogate Measures of Physical Activity and Physical Fitness. Evidence for Sedentary Traits of Resting Tachycardia, Obesity, and Low Vital Capacity. American Journal of Epidemiology, 129, 1145-1156. https://doi.org/10.1093/oxfordjournals.aje.a115236

Blair, S. N., LaMonte, M. J., \& Nichaman, M. Z. (2004). The Evolution of Physical Activity Recommendations: How Much Is Enough? American Journal of Clinical Nutrition, 79, 913S-920S. https://doi.org/10.1093/ajcn/79.5.913S

British Columbia Ministry of Health (1978). Physical Activity Readiness Questionnaire (PAR-Q). Multidisplinary Advisory Board on Exercise. Department of National Health and Welfare.

Dunn, A. L., Marcus, B. H., Kampert, J. B., Garcia, M. E., Kohl, H. W., \& Blair, S. N. (1997). Reduction in Cardiovascular Disease Risk Factor: 6-Month Results from Project Active. Preventive Medicine, 26, 883-892.

https://doi.org/10.1006/pmed.1997.0218

Durnin, J. V. G. A., \& Rahaman, M. M. (1967). The Assessment of the Amount of Fat in the Human Body from the Measurement of Skinfold Thickness. British Journal of Nutrition, 21, 681-688. https://doi.org/10.1079/BJN19670070

Durnin, J. V., \& Womersley, J. (1974). Body Fat Assessed from Total Body Density and Its Estimation from Skinfold Thickness: Measurements on $481 \mathrm{Men}$ and Women Aged from 16 to 72 Years. British Journal of Nutrition, 32, 77-97. https://doi.org/10.1079/BJN19740060

Kasch, F. W., \& Wallace, J. P. (1976). Physiological Variables during 10 Years of Endurance Exercise. Medicine \& Science in Sports and Exercise, 8, 5-8.

Kemper, H. C., Twisk, J. W., Koppes, L. L., Van Mechelen, W., \& Post, G. B. (2001). A 15-Year Physical Activity Pattern Is Positively Related to Aerobic Fitness in Young Males and Females (13 - 27 Years). European Journal of Applied Physiology, 84, 395-402. https://doi.org/10.1007/s004210100392

McMurray, R. G., Ainsworth, B. E., Harell, R. S., Griggs, T. R., \& Williams, O. D. (1998). Is Physical Activity or Aerobic Power More Influential on Reducing Cardiovascular Disease Risk Factors? Medicine \& Science in sport and Exercise, 30, 1521-1529.

McMurray, R. G., Harrell, J. S., Bangdiwala, S. I., \& Hu, J. (2003). Tracking of Physical Activity and Aerobic Power from Children through Adolescence. Medicine \& Science in Sports and Exercise, 35, 1914-1922. https://doi.org/10.1249/01.MSS.0000093612.59984.0E

Rose, G., McCartney, P., \& Reid, D. D. (1977). Self-Administration of a Questionnaire on Chest Pain and Intermittent Claudication. British Journal of Preventive Social Medicine, 31, 42-48.

Talbot, L. A., Morrell, Metter, E. J., \& Fleg, J. L. (2002). Comparison of Car- 
dio-Respiratory Fitness versus Leisure Time Physical Activity as Predictors of Coronary Events in Men Aged < or 65 Years and >65 Years. American Journal of Cardiology, 89, 1187-1192. https://doi.org/10.1016/S0002-9149(02)02302-0

Tuero, C., DePaz, J. A., \& Marquez, S. (2001). Relationship of Measures of Leisure Time Physical Activity to Physical Fitness Indicators in Spanish Adults. Journal of Sports Medicine \& Physical Fitness, 41, 62-67.

Tuxworth, W., Nevill, A. M., White, C., \& Jenkins, C. (1986). Health, Fitness, Physical Activity, and Morbidity of Middle-Aged Male Factory Workers. British Journal of Industrial Medicine, 43, 733-753.

Wilson, T. M., \& Tanaka, H. (2000). Meta-Analysis of the Age-Associated Decline in Maximal Aerobic Capacity in Men: Relation to Training Status. American Journal of Physiology. Heart and Circulatory Physiology, 278, H829-H834.

https://doi.org/10.1152/ajpheart.2000.278.3.H829 